\title{
Mechanical coating formed under conditions of vibration exposure
}

\author{
Vladimir Ivanov ${ }^{1}$, Sergey Popov $^{1,}{ }^{*}$, Nikolai Dontsov ${ }^{1}$, Galina Ekinil ${ }^{1}$, Julia Oleynikova ${ }^{1}$ and \\ Julia Denisenko ${ }^{1}$ \\ ${ }^{1}$ Don State Technical University, 1, Gagarin sq., 344003, Rostov-on-Don, Russia
}

\begin{abstract}
The study results of the zinc coating obtained on the surface of metals in the process of mechanochemical synthesis, implemented in the conditions of vibrowave systems, are presented. The features of coating formation mechanism, an activating role in its formation of free-moving, under the influence of low-frequency vibrations, indenters, are disclosed. The advantages of applying zinc coatings method in comparison with traditional methods are shown.
\end{abstract}

\section{Introduction}

The formation of a zinc coating on a metal surface under the conditions of vibrowave technological system is a complex process that is the result of the combined action of mechanical component and chemical reaction. When applying the coating by mechanochemical method, one of the main indicators of surface quality is provided, the absence of a hydrogenated layer.

The broad technological capabilities of vibrowave technological systems are the most effective means for obtaining high-quality, from the point of view of ensuring operational properties, coatings for various functional purposes on the surface [1-12]. Feature of the coating method considered in the article is that it is formed on the metal surface as a result of shock-pulse interaction of free-moving indenters in a closed volume under the influence of low-frequency oscillations. Insufficient knowledge of how this method influences on improving the operational properties of the metal surface predetermined the purpose of the research results.

The aim of the research is the formation mechanism of a zinc coating characterized by the presence of a double electric layer between the metal and the solution with the established equilibrium potential formed as a result of the vibrowave action of the freemoving indenter.

\section{Research results}

The formation of a coating as a result of the vibrowave action of free-moving indenters has its own specifics. So the formation mechanism of zinc coatings is characterized by the presence between the metal and the solution of a double electric layer with an established

* Corresponding author: spopov1957@yandex.ru 
equilibrium potential. Zinc ion reduction $\left(\mathrm{Z}_{\mathrm{n}}^{++}\right)$on metal is possible when the potential is shifted relative to the equilibrium value to the negative region. Under dynamic load conditions, the activation of the surface of metal, ions, atoms, molecules - all the components involved in the formation of a coating - sharply increases. Activated molecules and atoms acquire additional energy, helping to overcome the potential barrier that affects the chemical reactions rate. The activation process essence during vibrating mechanochemical treatment is to impart catalytic properties to the material surface with respect to the zinc ions reduction reaction. Increasing of zinc ions concentration in the boundary layer is facilitated by the circulation of free-moving indenters (working medium), at which the rate of discharged ions supply to the metal surface increases [13-28].

Vibrating mechanochemical zinc coating is applied at high activation and concentration of ingredients in the boundary layer, the electrode potential with respect to equilibrium shifts to values at which the zinc ion reduction reaction becomes possible.

The conclusion is confirmed by the results of the experiment on the deposition of the coating in time (fig. 1), as well as the Nernst equation:

$$
E_{p}=E^{0}+\frac{2,3 R T}{n F} \lg a_{m}^{n+},
$$

where $E_{p}$ - equilibrium electrolytic potential; $E^{0}$ - standard electrolytic potential; R absolute gas constant; $\mathrm{T}$ - absolute temperature; $\mathrm{n}$ - number of electrons involved in the reaction; F - Faraday number $\left(96493 \mathrm{Cl} / \mathrm{mol}\right.$ electrons); $a_{\mathrm{m}}{ }^{\mathrm{n}+}-$ metal ions activity in preparation.

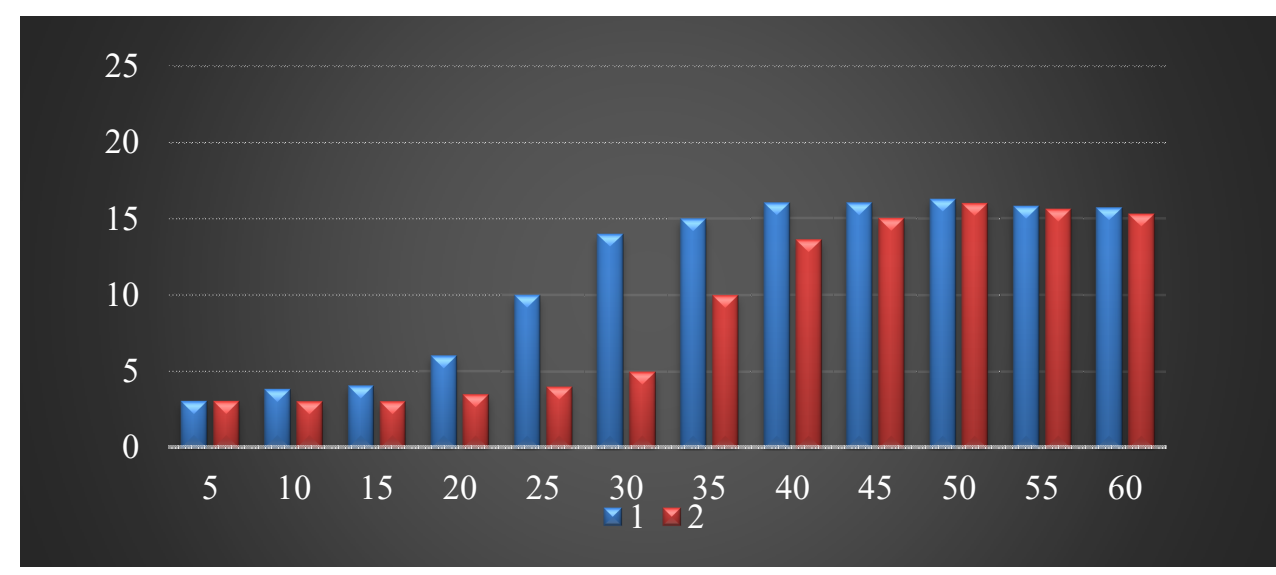

Fig. 1. The change in the zinc coating thickness on steel 40 from the length of the processing time in working environments: 1 - porcelain balls, diameter 5-10 mm; 2 - glass balls, diameter $5 \mathrm{~mm}$; Ordinate axis - Coating thickness, $\mu \mathrm{m}$; Abscissa axis - Time, min.

From equation (1) it can be seen that the ions activity can significantly affect the equilibrium potential.

Considering that the vibrating mechanochemical treatment process is accompanied by a high activation and concentration of ions located in the boundary layer, as well as the condition under which zinc is precipitated from simple salts with a slight overvoltage, we determine the activity of iron and zinc ions when the potential is shifted, for example, by -1 $\mathrm{V}$.

Substituting the corresponding values in equation (1), we obtain:

$$
-1=-0,43+0,029 \operatorname{lg~} \mathrm{a}_{\mathrm{m}}{ }^{\mathrm{n}+} \text {; }
$$




$$
\begin{gathered}
-0,57=0,029 \lg \mathrm{a}_{\mathrm{m}}{ }^{\mathrm{n}+} \\
\lg \mathrm{a}_{\mathrm{m}}{ }^{\mathrm{n}+}=-0,57 / 0,029=-20 ; \\
\mathrm{a}_{\mathrm{m}}{ }^{\mathrm{n}+}=10^{-20}
\end{gathered}
$$

For zinc:

$$
\begin{gathered}
-1=-0,76+0,029 \lg \mathrm{a}_{\mathrm{m}}{ }^{\mathrm{n}+} \\
-0,24=0,029 \lg \mathrm{a}_{\mathrm{m}}{ }^{\mathrm{n}+} \\
\lg \mathrm{a}_{\mathrm{m}}{ }^{\mathrm{n}+}=-0,24 / 0,029=-8 \\
\mathrm{a}_{\mathrm{m}}{ }^{\mathrm{n}+}=10^{-8}
\end{gathered}
$$

The calculation showed that the zinc ions activity at a given value of potentials at $10^{12}$ times more than the iron ions activity, therefore, there is a shift in equilibrium potentials.

Despite the lack of some data on the kinetics and mechanism of the process due to the complexity of its preparation, it can be considered established the zinc coating formation on steel parts. General condition for this is a vibrowave effect, providing in each case an adequate shift of the equilibrium potential [1-3].

The theory of the formation of coating (nuclei) initial phase during the metals crystallization is based on position of the new phase formation in the preparation-solid system. As the zinc coating nucleus, we should understand the crystalline, which consists of the minimum number of atoms necessary to build one unitary crystalline cell [4-7]. According to Gibbs theory, for the new phase formation, a certain supersaturation of the preparation with respect to the equilibrium value is necessary. Due the vibrating mechanochemical treatment supersaturation is associated with the activation and concentration of reagents in the boundary layer, providing a potential shift.

In accordance with classical theory, the radius of a three-dimensional nucleus of critical size $\left(r_{3}\right)$ described by the Thomson equation:

$$
\mathrm{r}_{3}=2 \sigma_{\mathrm{m}} \mathrm{V} /\left(\mathrm{nF} \eta_{\mathrm{cr}}\right)
$$

where $\sigma_{\mathrm{m}}-$ Gibbs specific interphase energy of the metal-preparation interface; $\mathrm{V}$ - metal molecular volume; $\mathrm{n}$ - metal ion charge; $\mathrm{F}$ - Faraday number; $\eta_{\mathrm{cr}}$ - crystallization overvoltage.

$$
\eta_{\mathrm{cr}}=E-E_{p}=\frac{2,3 R T}{n F} \lg \frac{C}{C_{p}}
$$

where $\mathrm{C}$ - surface concentration; $\mathrm{C}_{\mathrm{p}}$ - equilibrium concentration.

The change in the energy of the system during the formation of a crystalline size nucleus is associated with the appearance of a nucleus - solution interface and the formation of a new phase volume. The expression for the change in Gibbs energy during the formation of a three-dimensional nucleus has the form:

$$
\Delta G_{3}=16 \pi \sigma_{M}^{3} V^{2} /\left(3 n^{2} F^{2} \eta \eta_{c r}^{2}\right) .
$$

The rate of nucleation is related to the energy of their formation by the ratio: 


$$
\frac{d N}{d \tau}=K_{\exp }[-\Delta G /(R T)]
$$

where $\mathrm{N}$ - number of nuclei; $\mathrm{K}$ - speed constant.

Thus, for the rate of formation of three-dimensional nuclei, we obtain the equation

$$
\frac{d n}{d \tau}=K_{3 \exp }^{\mid}\left(-K_{3} / \eta \eta_{c r}^{2}\right)
$$

This equation establishes the relationship between the number of nuclei formed and overvoltage.

According to Gibbs, the formation of a new phase is similar to the new atomic plane formation. Crystal growth pattern during formation of vibrating mechanochemical zinc coating can be represented as follows.

An electromotive force (microelement field) arises between the crystals of the resulting coating and the surface of the metal being coated, which has a significant effect on the further course of coating formation. Under conditions of high activity, the formation of crystalline nuclei occurs not only on the protrusions, but also on the faces. During coating growth, the appearance of dislocations acting as an active center may be observed. As a result, the metal is coated evenly, the crystals are closed, forming a continuous fine crystalline coating. This initial layer is the substrate for subsequent coating growth. As the coating grows, small groups of crystals grow along the metal surface. Under the influence of vibrowave and collision of the working medium, micro/nanoparticles of zinc powder, falling into of electric forces action sphere, are simultaneously compacted by it with a growing precipitate, forming a continuous coating [6] (Fig. 2).

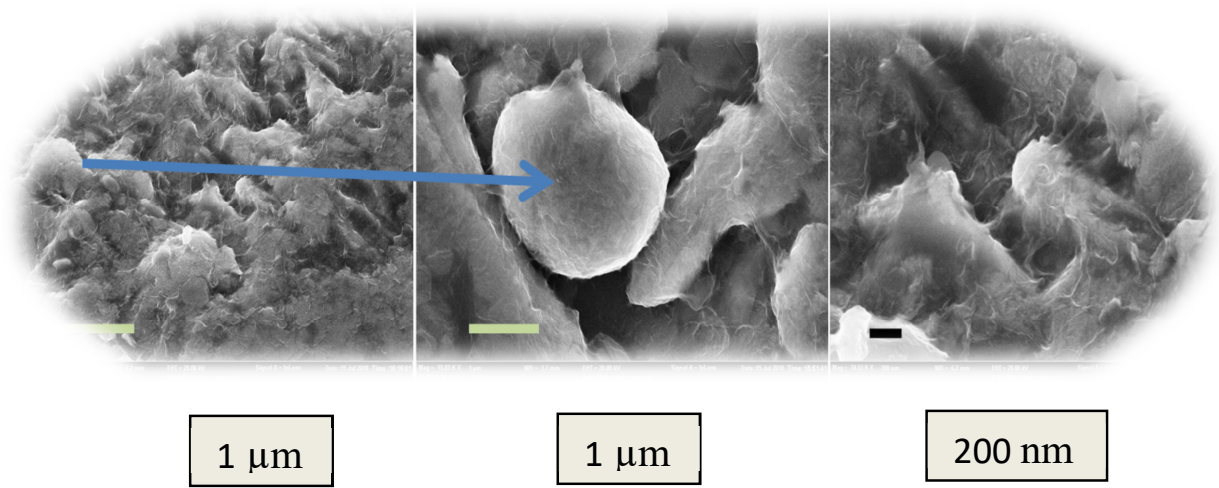

Fig. 2. Surface morphology of the vibratory mechanochemical zinc coating at various magnifications: $\mathrm{T}=20 \mathrm{~min} ., \mathrm{A}=3 \mathrm{~mm}$.

Convection movement leads to a decrease in the thickness of the double layer, which allows to reduce diffusion restrictions and increase the speed of the process. Experimental studies have shown that the formation of a large number of micro/nanocrystals provides more complete overlap of the base metal. The result is less porosity, high corrosion resistance and adhesive strength of the coating [7,8]

Presented chemical processes that occur during the vibrating mechanochemical zinc coating formation, accompanied by metal surface layers elastoplastic deformation under conditions of multiple dynamic contact of the working medium particles with detail.

Figure 3 shows the initial surface of steel 45 and the imprint obtained by incorporating a 
porcelain ball with a diameter of $10 \mathrm{~mm}$ into the surface layer of the coating at a relative strain rate equal to $43750 \mathrm{c}^{-1}$. Analysis of the sample surface showed that in the area of contact between the balls and the surface, a large number of zinc coating crystals were observed, merged together. Separate grains of zinc powder were noted along its boundaries. The formed zinc coating crystals are randomly located on the metal surface.

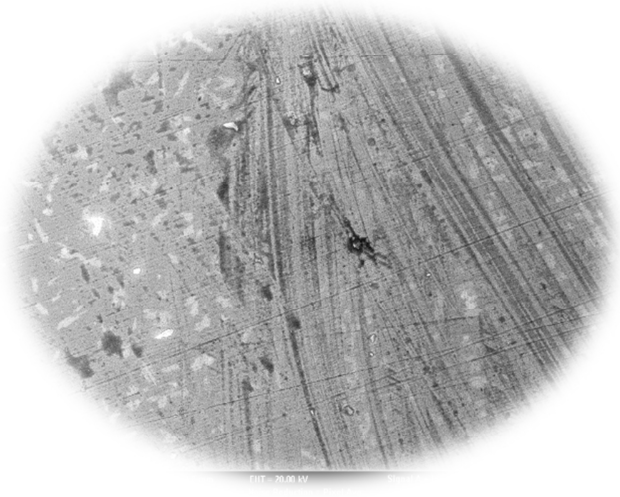

a)

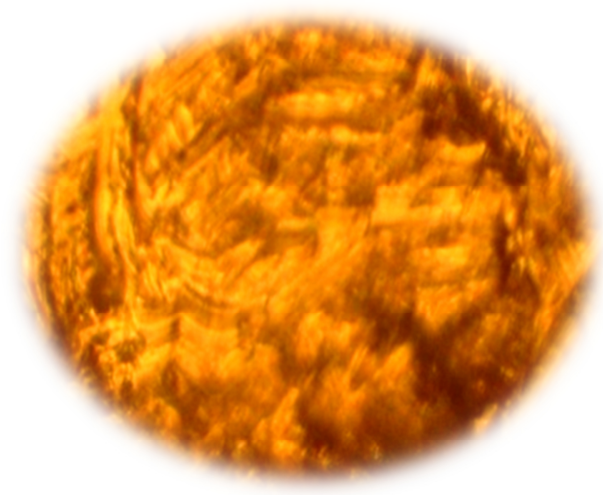

b)

Fig. 3. a - Initial surface steel 45, scale - 20 microns; b - imprint of the contact area of the steel oxidized surface 3 after the introduction of porcelain ball (x 240).

The pores and dislocations that occur are the result of vibrowave system. Shallow deepenings and longitudinal uniform risks of various shapes and sizes are visible on the test surface, which is a consequence of direct and oblique strokes $[9,10]$.

Such a nature of the arrangement of zinc crystals in the coating is possible to obtain only as a result of vibrowave exposure. Thin section analysis of vibrating mechanochemical zinc coating showed, that the coating and substrate have an identical metallic nature, the absence of a sharp boundary between them and the hydrogenated surface layer (Fig. 5.a). The electrodeposited coating presented for comparison in (Fig.5.b) is characterized by porosity, a sharp metal-substrate interface, and the presence of a hydrogenated layer, which impairs its performance compared to vibrating mechanochemical zinc coating.

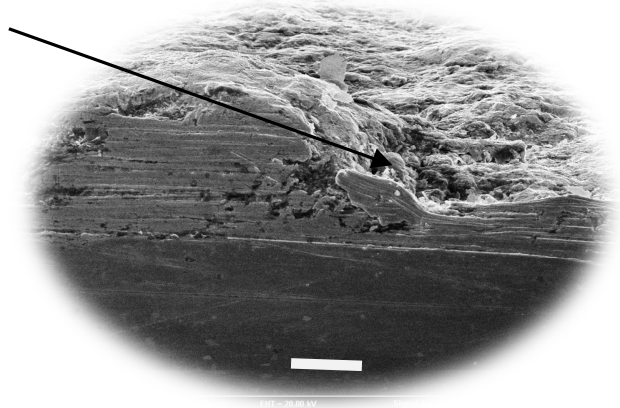

a)

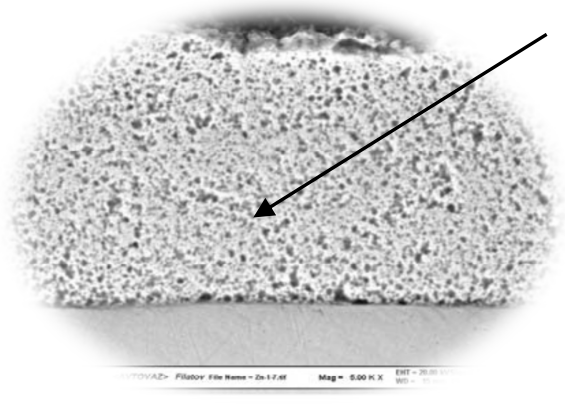

b)

Fig. 4. Thin section; a - vibrating mechanochemical zinc coating, scale - 20 microns; b - galvanic zinc coating, scale -10 microns.

\section{Conclusions}

1. Zinc coating applied to metal surfaces under the influence of free-moving indenters has 
increased corrosion properties compared to the coating obtained by traditional technology due to the absence of a hydrogenated layer.

2. The studies clearly showed that the formation mechanism of the zinc coating under the conditions of the vibrowave exposure to free-moving indenters largely predetermined the operational properties of the coating.

3. Applying a vibrating mechanochemical zinc coating allows during processing: to activate the metal surface layer as a result of shock-pulsed exposure, to increase the surface layers dislocation density, to carry out the oxide films destruction, to ensure effective coating.

\section{References}

1. V.V. Ivanov, S.I. Popov, E.M. Selemeneva, N.T. Babazhanov, AIP Conference Proceedings 2188, 020015-1-020015-5 (2019) doi.org/10.1063/1.5138389

2. V.V. Ivanov, S.I. Popov, Ju.V. Marchenko, E.V. Marchenko, N.S. Dontsov, S.A. Timofeev, IOP Conference Series: Earth and Environmental Science 403, 012115 (2019) doi:10.1088/1755-1315/403/1/012115

3. A.A. Korotky, E.V. Marchenko, V.V. Ivanov, S.I. Popov, Ju.V. Marchenko, N.S. Dontsov, IOP Conference Series: Earth and Environmental Science 403, 012116 (2019) doi:10.1088/1755-1315/403/1/012116

4. A.A. Kotesova, S.V. Teplyakova, S.I. Popov, F.C. Kopylov, IOP Conference Series: Materials Science and Engineering 698, 066029 (2019) doi:10.1088/1757899X/698/6/066029

5. V.V. Ivanov, S.I. Popov, A.V. Kirichek, IOP Conference Series: Materials Science and Engineering 327, 032026 (2018) doi:10.1088/1757-899X/327/3/032026

6. V.V. Ivanov, N.S. Dontsov, A.V. Kirichek, IOP Conference Series: Materials Science and Engineering 327, 032025 (2018) doi:10.1088/1757-899X/327/3/032025

7. V.V. Ivanov, N.P. Pogorelov, N.S. Dontsov, Y.N. Denisenko, AIP Conference Proceedings 2188, 020005 (2019) doi.org/10.1063/1.5138379

8. N.N. Nikolaev, Yu.V. Marchenko, S.K. Filatov, IOP Conference Series: Materials Science and Engineering 698, 066027 (2019) doi:10.1088/1757-899X/698/6/066027

9. D. Evseev, A. Kotesova, V. Kosenko, A. Golubeva, IOP Conference Series: Materials Science and Engineering 698, 066032 (2019)

10. V. Kasyanov, V. Deryushev, L. Shulkin, E. Kosenko, A. Kotesova, MATEC Web Conf. 224, 02107 (2018) doi.org/10.1051/matecconf/201822402107

11. V. Deryushev, M. Zaitseva, G. Megera, A. Fedyanov, IOP Conference Series: Materials Science and Engineering 698, 066031 (2019)

12. T. Rogovenko, M. Zaitseva, Materials Science Forum 931, 417-421 (2018) doi.org/10.4028/www.scientific.net/MSF.931.417

13. A. Ivakhnenko, M. Storublev, A. Ivakhnenko, Procedia Engineering 150, 742-745 (2016) doi:org/10.1016/j. proeng.2016.07.097

14. V. Smolentsev, A. Boldyrev, E. Smolentsev, A. Boldyrev, V. Mozgalin, IOP Conference Series: Materials Science and Engineering 327(4), 042015 (2018) doi:10.1088/1757-899X/327/4/042015

15. V. Ilyasov, B. Meshi, D. Pham, C. Nguyen, O. Holodova, T. Zhdanova, I. Ershov, N. Prutsakova, I. Popova, Springer Proceedings in Physics 207, 127-144 (2018) doi:10.1007/978-3-319-78919-4

16. A. Khoroshev, A. Pavlenko, A. Korotky, D. Tchout, V. Puzin, E. Khorosheva, IOP 
Conference Series: Materials Science and Engineering 177(1), 012072 (2017) doi:10.1088/1757-89 012072

17. V. Blumenstein, M. Mahalov, A. Shirokolobovam, IOP Conference Series: Materials Science and Engineering 253(1), 012017 (2017) doi:10.1088/1757-899X/253/1/ 012017

18. V.A. Lebedev, V.V. Ivanov, V.P. Fedorov, Materials Science and Engineering 124 (2016) doi.10.1088 / 1757-899X / 124/1/012160. R.1-6

19. V.P. Smolentsev, A.I. Portnykh, V.V. Ivanov, IOP Conf. Series: Materials Science and Engineering 327, 042121 (2018) doi: 10.1088 / 1757-899X / 327/4/042121

20. S.I. Kambulov, I.V. Bozhko, A.V. Olshevskaya, MATEC Web of Conferences 224, 05022 (2018) https://doi.org/10.1051/matecconf/201822405022

21. A. Altybayev, A. Zhanbyrbayev, B. Meskhi, D. Rudoy, A. Olshevskaya, A. Prohorova, E3S Web of Conferences 135, $01078 \quad$ (2019) https://doi.org/10.1051/e3sconf/201913501078

22. B. Meskhi, B. Golev, V. Efros, D. Rudoy, A. Olshevskaya, V. Zhurba, Y. Chayka, E3S Web of Conferences 135, 01083 (2019) https://doi.org/10.1051/e3sconf/201913501083

23. J. Gerber, A. Zavaly, A. Gavrilov, A. Olshevskaya, N. Kiyan, IOP Conf. Series: Earth and Environmental Science 403, 012014 (2019) doi:10.1088/1755-1315/403/1/012014

24. G. Parkhomenko, S. Kambulov, A. Olshevskaya, A. Babadzhanyan, N. Gucheva, I. Mekhantseva, IOP Conf. Series: Earth and Environmental Science 403, 012144 (2019) doi:10.1088/1755-1315/403/1/012144

25. A.A. Kostoglotov, D.S. Andrashitov, A.S. Kornev, S.V. Lazarenko, Measurement Techniques 62, 497-502 (2019) DOI: 10.1007/s11018-019-01652-8

26. S.V. Lazarenko, A.A. Kostoglotov, Journal of Communications Technology and Electronics 62(2), 123-127 (2017) DOI: 10.1134/S1064226917020061

27. A.A. Kostoglotov, I.V. Pugachev, S.V. Lazarenko, AIP Conference Proceedings (2019) DOI: $10.1063 / 1.5138398$

28. S.V. Lazarenko, A.A. Kostoglotov, A.I. Kostoglotov, Journal of Communications Technology and Electronics 54(4), 431-438 (2019) DOI: $10.1134 / \mathrm{S} 1064226909040081$ 